\title{
TRAUMATIC DIAPHRAGMATIC HERNIA: ANAESTHETIC CONSIDERATION
}

Raghu Nandan Khadgaray, ${ }^{1}$ Santosh Shah, ${ }^{2}$ Pawan Puspa Baral ${ }^{1}$

\begin{abstract}
Any type of trauma may lead to diaphragmatic hernia with blunt forces accounting for majority. Diaphragmatic hernias require a high level of suspicion to detect. Brain, pelvis, long bones, liver, spleen, and aorta are some other organs that can be severely damaged and need different anesthetic management. Gastric decompression, pre-oxygenation, rapid sequence induction and mechanical ventilation with low tidal volume after intubation were used in anesthetic management for thoracotomy and repair. Traumatic diaphragmatic hernia can be life threatening as it may compromise cardiorespiratory function.
\end{abstract}

KEYWORDS Anesthesia, diaphragmatic hernia, thoracotomy

1. Department of Anasthesiology, Universal College of Medical Sciences, Bhairahawa, Nepal

2. Department of Surgery (CTVS), Universal College of Medical Sciences, Bhairahawa, Nepal

DOI: https://doi.org/10.3126/jucms.v6i2.22501

\author{
For Correspondence \\ Dr. R.N. Khadgaray \\ Department of Anaesthesia \\ Universal College of Medical Sciences \\ Bhairahawa, Nepal \\ Email: dr.rnkhadgaray@gmail.com
}




\section{INTRODUCTION}

Diaphragmatic rupture can be seen in up to $5 \%$ of road traffic accidents (RTA), and $80-100 \%$ of diaphragmatic hernias are associated with other vital organ injuries. ${ }^{1}$ Patients can be asymptomatic in up to $53 \%$ of hernias from blunt trauma. The respiratory distress and circulatory changes due to prolapse of abdominal organs into thoracic cavity is main pathophysiological changes to be considered. The main anesthetic consideration includes invasive monitoring and smooth intubation and extubation to prevent coughing and straining which leads to intra abdominal pressure and may result of sudden diaphragmatic rupture.

\section{CASE REPORT}

A 32-year-old gentleman, victim of a road traffic accident was brought to Universal College of Medical Sciences, Bhairahawa, Nepal. In the first assessment, the patient was in sitting position, was alert (Glasgow Coma Scale $[\mathrm{GCS}]=15$ ), and did not have shortness of breath. Vital signs were as follows: blood pressure $(\mathrm{BP})=130 / 100 \mathrm{~mm} \mathrm{Hg}$; heart rate $(\mathrm{HR})=100$; respiratory rate $(\mathrm{RR})=9$; temperature $37^{\circ} \mathrm{C}$, and $\mathrm{O}_{2}$ saturation $90 \%$ (breathing room air). There was no sign of neck vein engorgement, deviation of trachea, subcutaneous emphysema, rhinorrhagia, otorrhagia, or cerebrospinal fluid (CSF) leakage. Decreased breathing sound was detected in the left lung. Tenderness in left upper quadrant (LUQ) was recorded. Computed tomography (CT) scan and chest X-ray indicated gastric herniation into left thoracic space. Patient lab data were as follows: hemoglobin $(\mathrm{Hb})=9.8$; hematocrit $(\mathrm{Hct})=31$; prothrombin time $(\mathrm{PT})=13$. International normalized ratio $(\mathrm{INR})=1$; blood urea nitrogen $(\mathrm{BUN})=18$; creatinine $=1.3 ; \mathrm{Na}=145, \mathrm{~K}=4 ;$ blood sugar $(\mathrm{BS})=193$; $\mathrm{P}^{\mathrm{H}}=7.27 ; \mathrm{PCO}_{2}=5 ; \mathrm{PO}_{2}=132$. Two hours after admission, patient felt dyspnea in the sitting position. However, no changes in hemodynamic parameters were noted, and $\mathrm{O}_{2}$ saturation was $97 \%$ with oxygen mask.

About 6 hours after the accident, the patient was sent to the operating room. His vital signs were stable. Oxygen saturation $\left(\mathrm{SpO}_{2}\right)$ was $86 \%$ (room air). Volume replacement was done with $1000 \mathrm{~mL}$ of Lactated Ringer's solution. A nasogastric tube was already fixed in the emergency room. A large-bore IV lines along with central venous catheterization was done on right sided internal jugular vein. Standard monitoring and arterial line were installed. Thoracic epidural catheter was fixed at T7 level. Fentanyl $150 \mathrm{mcg}$ IV and $2 \mathrm{mg}$ of IV midazolam were administered as premedication following by pre-oxygenation. Propofol $160 \mathrm{mg}$ and succinylcholine 100 $\mathrm{mg}$ were used for induction. The patient was intubated with a single lumen endotracheal tube. Vecuronium $4 \mathrm{mg}$ was administered after return of muscle activity and mechanical ventilation was started with low tidal volume. Anesthesia was maintained with isoflurane and oxygen. Surgery with a left thoracotomy approach was started immediately after positioning (right lateral decubitus). After the chest was opened, the patient found to have a large diaphragmatic tear from diaphragmatic dome to central tendon with herniation of stomach and omentum into left hemithorax. Viscera were pushed back into the abdominal cavity, and the diaphragmatic tear was repaired. No hemodynamic change was recorded in this period. At the end of the thoracotomy, a chest tube was inserted in the left thorax. The patient was turned into a supine position. Epidural was activated with $0.125 \%$ bupivacaine with fentanyl $50 \mathrm{mcg}$. At the end of surgery, the patient's spontaneous respiration was returned. The patient was extubated as soon as he was conscious, and his reflexes recovered. He was under monitoring in the post-anesthesia care unit for one hour, and was sent to the intensive care unit. The patient was discharged after 4 days without any postoperative complications. Photograph of preoperative chest X-ray PA view depicted as per figure 1 .

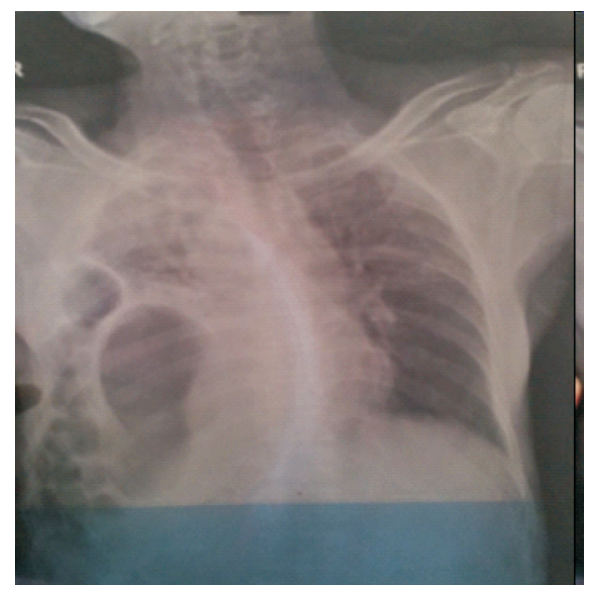

Figure 1. Photograph of preoperative chest X-ray PA view

\section{DISCUSSION}

Diaphragmatic hernia can compromise cardiorespiratory function by different mechanisms. Paraclinical diagnostic methods are usually not conclusive. In $30-69 \%$ of patients, the diagnosis is made during surgery. In $4.5-15 \%$ of cases, the diagnosis remained undiscovered in the postoperative period. Peritoneal lavage, thoracoscopy, and laparoscopy are also used to confirm the diagnosis of diaphragmatic hernia. A high degree of suspicious is always the key for rapid diagnosis. Severity of coexisting injuries is the major determinant of the high mortality rate (13-25\%) and urgent surgery is usually indicated. $^{1,2}$

Although different anesthetic methods have been proposed for 
management of these patients, the usual recommended methods of anesthesia are awake intubation, crash induction, NG tube insertion, avoidance of mask ventilation, and one lung ventilation. ${ }^{3}$

The role of increased visceral volume in the thoracic cavity is prominent in the pathophysiology of the disease, and the stomach is the most common herniated viscera; therefore, decompression of the stomach and avoiding bag mask ventilation (rapid sequence induction with succinylcholine) are crucial. In contrast, avoiding succinylcholine administration in patients with high intracranial pressure, open globe, and penetrating neck wounds is not strictly necessary. If there are no other major hemodynamic compromises like hemorrhage or heart contusion, it would be better to use high doses of hypnotic drugs. ${ }^{3-5}$

Lobb and Butlin reported a diaphragmatic hernia patient with basal skull fracture who was intubated in an awake state and then spontaneously ventilated with a mixture of nitrous oxide. Basal skull fracture seemed not to be a primary concern for the authors; their greater priority was hemodynamic stability. ${ }^{2}$

Loehning et al found a chance for viscera to be pushed into the thoracic cavity by the contralateral diaphragm via relaxed dilated hole of the perforated diaphragm during mechanical ventilation. Spontaneous ventilation always carries the risk of cough. Some authors believe that positive pressure ventilation can prevent viscera from entering the thoracic cavity. This is supported by some clinical observations, i.e., the less suggestive or diagnostic chest x-rays of diaphragmatic hernia in intubated patients or progressive herniation of abdominal viscera after termination of ventilatory support. ${ }^{6}$

Williams et al recommended double lumen tubes and one lung ventilation for patients with diaphragmatic hernia. Double lumen tube insertion is time consuming and is associated with a higher failure rate. They did not succeed in inserting such a tube and changed it to an endo-bronchial single lumen tube, which kept the other bronchus unprotected during the whole length of surgery. Air trapping, pneumothorax, ventilation failure caused by tube misplacement, and airway trauma are other disadvantages of double lumen tubes.

\section{CONCLUSION}

Invasive monitoring of arterial line and central venous pressures before induction in a calm and cooperative patient is helpful. For this group of patients, we recommend rapid sequence induction with the use of succinylcholine, complete dose of induction agents (if there are no hemodynamic compromises), and avoidance of mask ventilation before intubation. A single lumen tracheal tube expedites the process, and immediate non-depolarizing muscle relaxant administration prevents patient strain after induction of anesthesia. Mechanical ventilation with low tidal volume and rapid start of the surgical procedure may prevent the negative effects of involved pathophysiologies. We do not recommend awake intubation and spontaneous ventilation in these patients. Nitrous oxide can also be detrimental, and the efficacy of the double lumen tube is undetermined. Given that brain injury is the leading cause of mortality and some cases of traumatic brain injuries are still undiagnosed at the time of emergency surgery, our recommendations could be applicable for the majority of traumatic diaphragmatic hernias.

\section{REFERENCES}

1. Meyers FB, McCabe CJ. Traumatic diaphragmatic hernia. Occult marker of serious injury. Ann Surg. 1993;218(6):783-90.

2. Lobb TR, Butlin GR. Anaesthesia and traumatic diaphragmatic hernia. Can AnaesthSoc J. 1974;21(2):173-80.

3. Yee LL, Rubin AS, Bellamy RF. Chapter 19, Thoracic Injuries. Anesthesia and Perioperative Care of the Combat Casualty. In: Zajtchuk R, Grande CM, editors. Textbook of Military Medicine Series, Vol 1, Part IV, Surgical Combat Casualty Care. Washington, DC: Office of The Surgeon General, Department of the Army, USA; 1995. pp. 455-77.

4. Gwely NN. Outcome of blunt diaphragmatic rupture. Analysis of 44 cases. Asian CardiovascThorac Ann. 2010;18(3):240-43.

5. Lee WJ, Lee YS. Traumatic diaphragmatic rupture: Adiagnostic challenge in the emergency department. BMJ Case Rep, 2009. 2009:bcr2006040451.

6. Loehning RW, Takaori M, Safar P. Circulatory collapse from anesthesia for diaphragmatic hernia. Arch Surg. 1965;90: 109-14.

7. Williams DJ, Sandby-Thomas MG. Anaesthetic management of acute gastric volvulus in an adult. Br J Anaesth. 2003;90 (1):96-98. 